\title{
Notes on the vocalizations of Eastern Meadowlark (Sturnella magna)
}

\section{Peter Boesman}

In the following we briefly analyze and compare voice of the different races of Eastern Meadowlark (Sturnella magna). We also try to quantify the extent of any vocal differences using the criteria proposed by Tobias et al. (2010), as a support for taxonomic review.

We have made use of sound recordings available on-line from Xeno Canto (XC) and Macaulay Library (ML).

Our main interest is to compare Cuban race hippocrepis with other races. Song of S. magna typically is a short phrase of melodious whistles. There is however quite some variation. Some examples:

Group1

USA (magna)

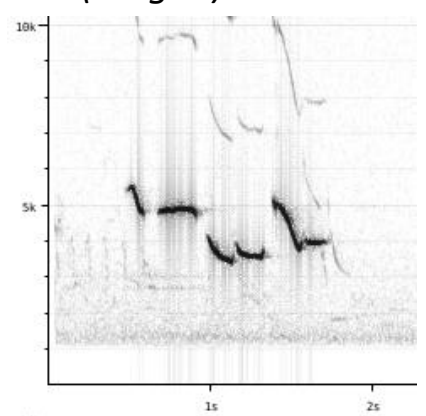

Group 2

Honduras

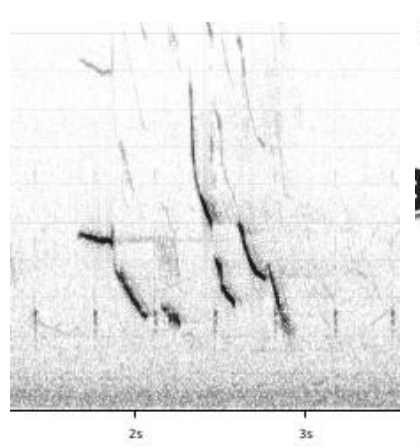

$\underline{\text { Group } 3}$

East Andes (meridionalis)

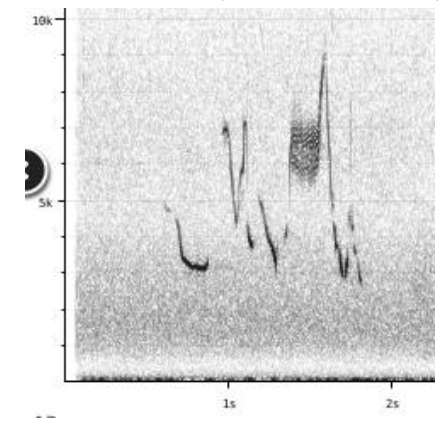

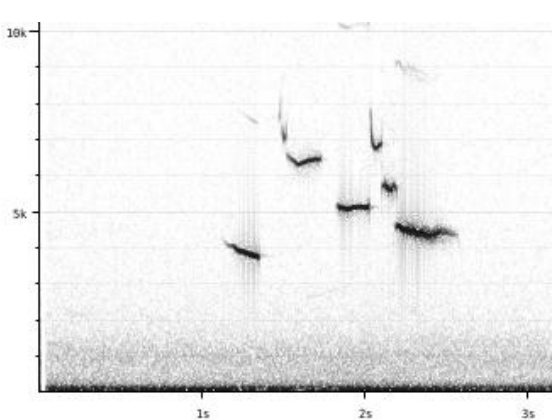
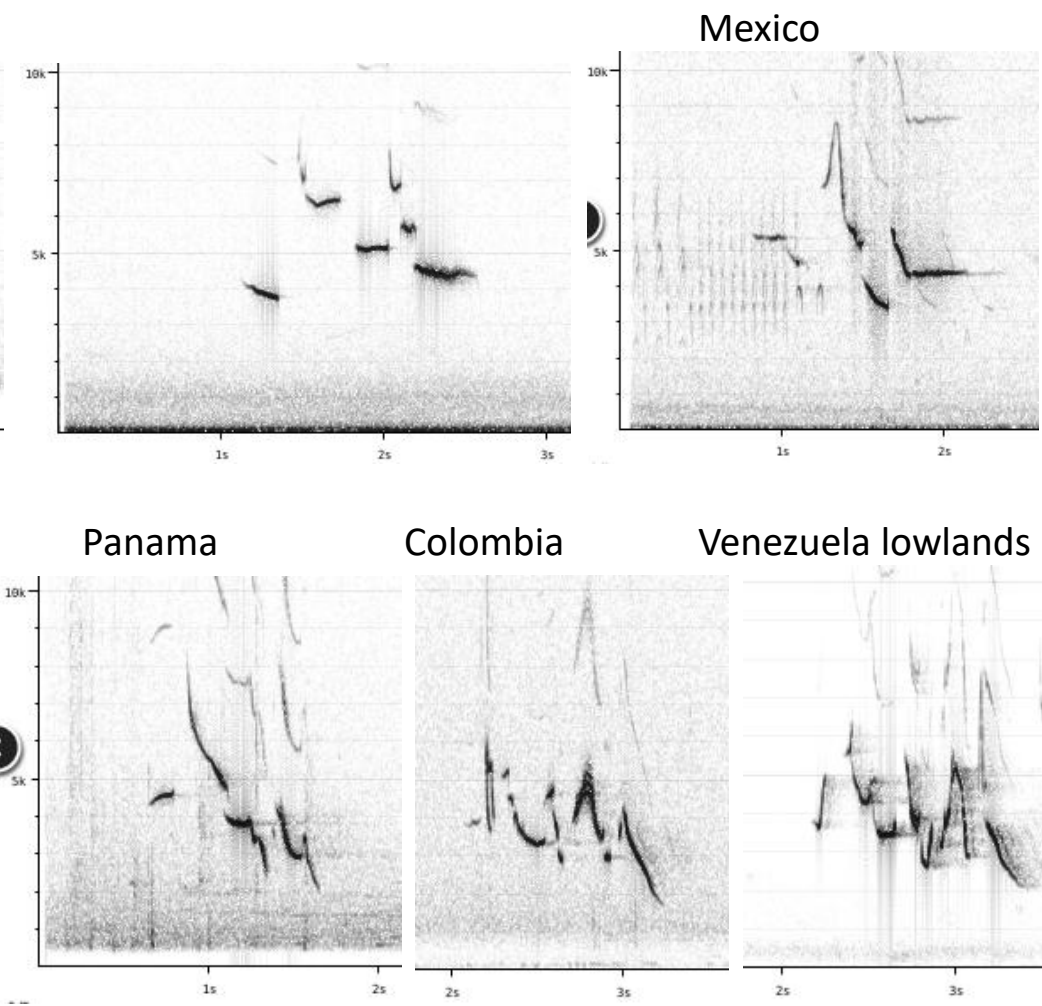

Colombia

Venezuela lowlands
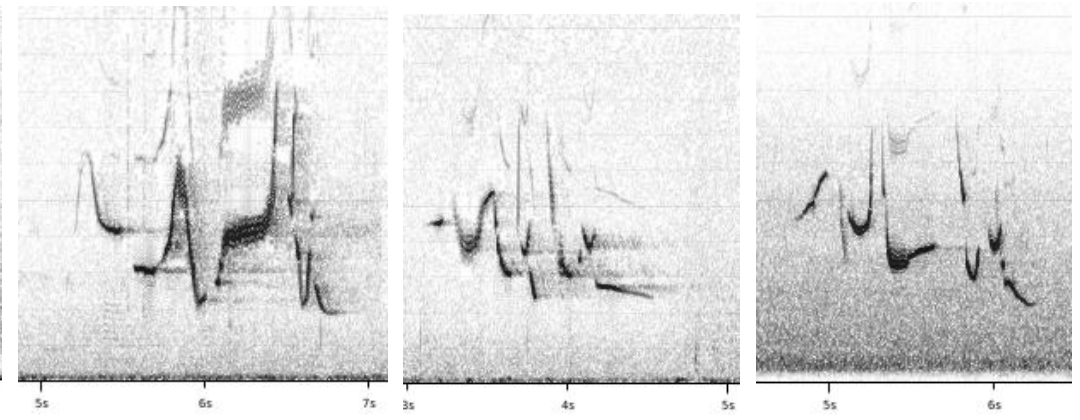


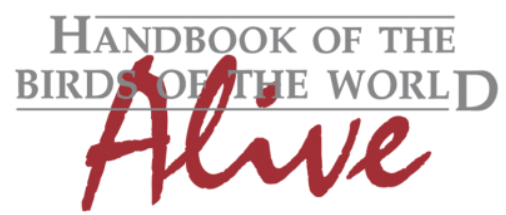

\section{ORNITHOLOGICAL NOTES}

Main differences between these three vocal groups are:

Group 1: mainly whistles at about flat pitch in USA and E Mexico

Group 2: steeply downslurred whistles in Central and South-America (also lilianae)

Group 3: several upslurred or underslurred whistles and some notes distinctly buzzy in East Andes of Venezuela and NE Colombia

The exact boundaries of these groups and whether there is a clinal change or not should be further investigated.

There are 3 recordings available of the Cuban race hippocrepis:

Song
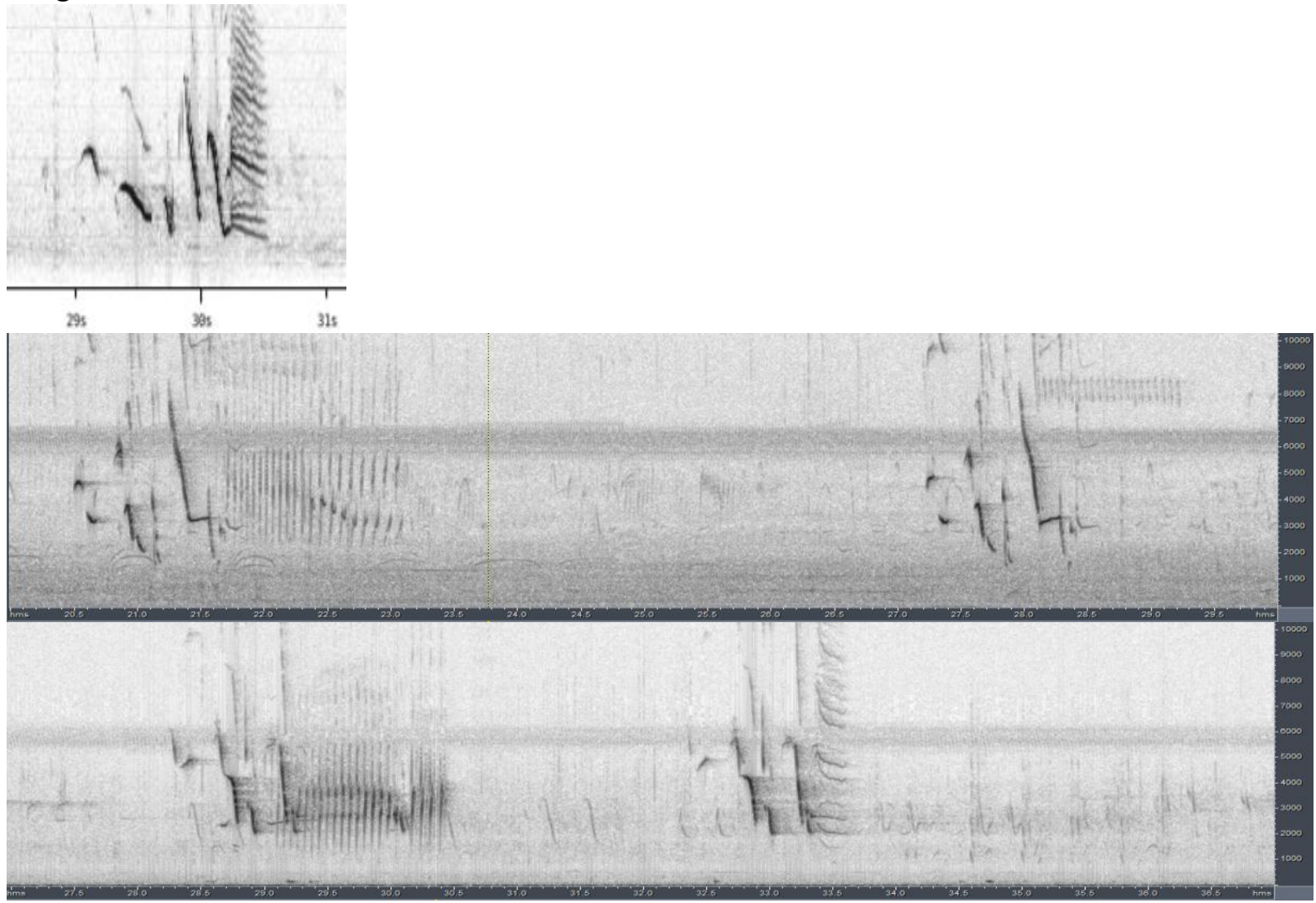

Call

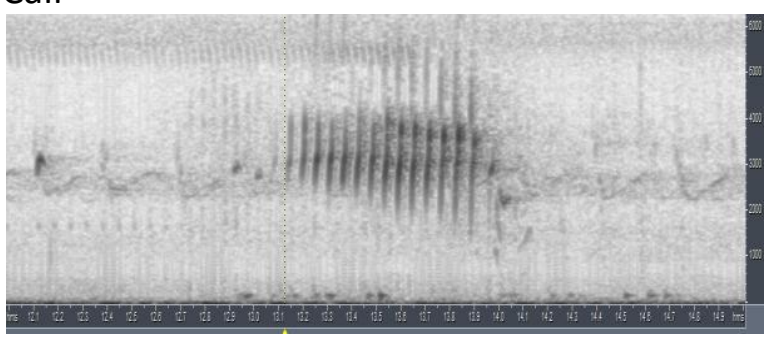

Song of hippocrepis seemingly consists of a number of short whistles, typically followed by either a nasal note or a rattling series of notes. Whistled notes are less slurred than in other races, and initial notes are much shorter. The last whistle before the nasal note or rattle (bisyllabic or in 2 parts) is emphasized and covers the widest freq. range. Overall this results in a quite rhythmic song "twee...tzee.che...tseee-whee". 

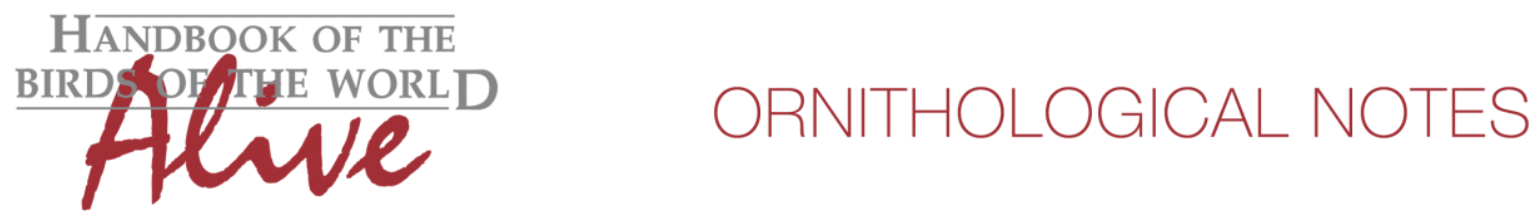

Amongst the other races, there is obviously some variation, but songs typically do not end with a nasal buzz or rattle (score 2 ) and initial notes on average are longer and whistles typically more slurred (score 1 ).

We only have a single call from Cuba, which we can compare with homologous calls of other races:

USA
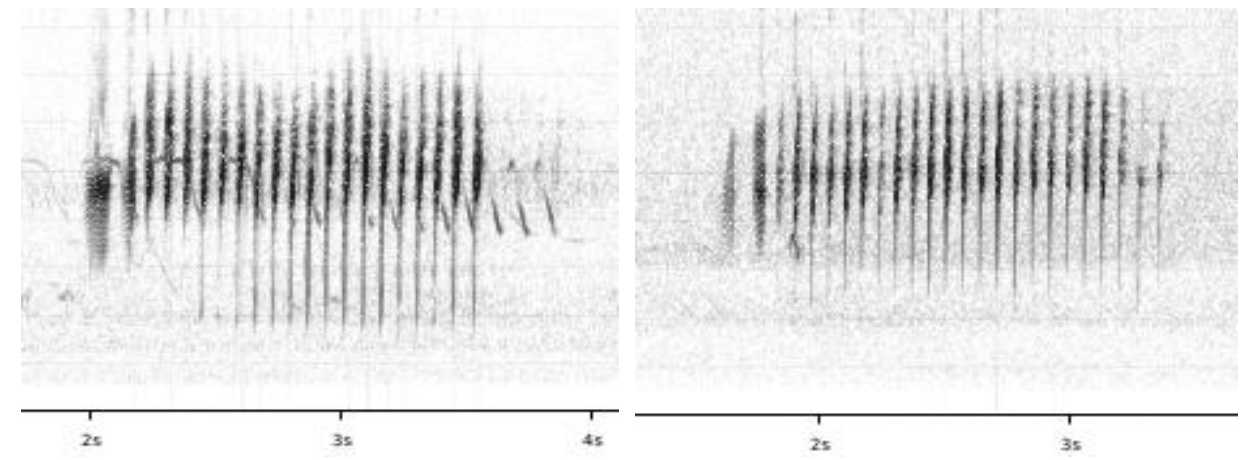

Panama

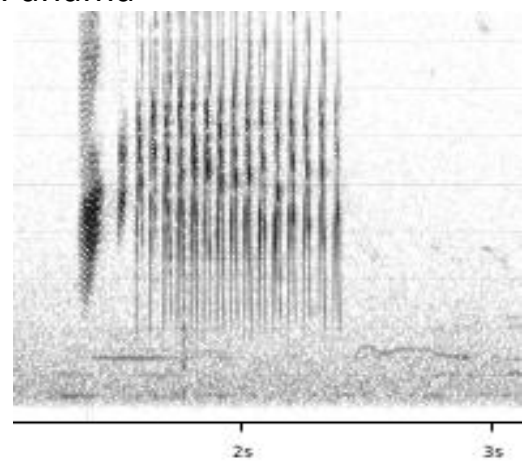

Venezuela

This single recording from Cuba seems to be lower-pitched (with most of the energy between 2 and $4 \mathrm{kHz}$ ) than typical calls of other races (with most of the energy between 4$6 \mathrm{kHz})$.

In literature, voice of Cuban race was e.g. discussed by Walkinshaw (1946) who noted: "the voice differed, resembling the words ze-te-zwe-zwee. The scolding note was harsher too".

We can conclude that voice of hippocrepis differs from other races (total vocal score about 3 ), but equally so there are likely more vocal groups to be distinguished in the other races. A more in depth study is clearly needed.

This note was finalized on 27th May 2016, using sound recordings available on-line at that moment. We would like to thank the many sound recordists who placed their recordings for this species on XC and ML, in particular Michael Anderson, Timothy Burr and Hans Matheve for the recordings from Cuba. 


\section{References}

Walkinshaw, L.H. \& Baker, B.W. (1946). Notes on the Birds of Isle of Pines, Cuba. The Wilson Bulletin Vol. 58: p 133-195.

Tobias, J.A., Seddon, N., Spottiswoode, C.N., Pilgrim, J.D., Fishpool, L.D.C. \& Collar, N.J. (2010). Quantitative criteria for species delimitation. Ibis 152(4): 724-746.

\section{Recommended citation}

Boesman, P. (2016). Notes on the vocalizations of Eastern Meadowlark (Sturnella magna). HBW Alive Ornithological Note 367. In: Handbook of the Birds of the World Alive. Lynx Edicions, Barcelona. (retrieved from http://www.hbw.com/node/1252917 on 2 November 2016). 